\title{
Measurement, evaluation, and assessment of peripheral neurological disorders caused by hand- transmitted vibration
}

\author{
Michael J Griffin $\bowtie$ \\ Human Factors Research Unit \\ Institute of Sound and Vibration Research \\ University of Southampton \\ Southampton SO17 1BJ \\ Telephone: (+44) 02380592853 \\ Facsimile: (+44) 02380592927 \\ e-mail: M.J.Griffin@soton.ac.uk
}

Work presented at the 2nd International Workshop 2006 on Diagnosis of Hand-Arm Vibration Syndrome in Göteborg, Sweden. 


\begin{abstract}
Regular exposure to hand-transmitted vibration can result in symptoms and signs of peripheral vascular, neurological and other disorders collectively known as the handarm vibration syndrome. The measurement of the effects of hand-transmitted vibration involves converting the evidence of disorder (symptoms and signs) into information that can be stored. Evaluation requires the use of scales on which to indicate the severity of the various symptoms and signs. Assessment involves a judgement of severity relative to a criterion, usually for a specific purpose (e.g. to decide on removal from work or compensation). The measurement and evaluation of symptoms and signs is necessary when monitoring patient health and when performing epidemiological studies for research. The assessment of the severity of the hand-arm vibration syndrome is currently performed with staging systems, but the criteria are not clear and not related to defined methods for measuring or evaluating the symptoms and signs. Recognising that similar symptoms can occur without injury from occupational exposures to hand-transmitted vibration, this paper attempts to define significant peripheral neurological symptoms caused by hand-transmitted vibration (i.e. 'unusual symptoms') and how these symptoms and related signs may be measured. Scales for evaluating the symptoms (e.g. their extent) and the related signs (e.g. their probability relative to the probability of the sign being present in persons not exposed to vibration) are defined. A method of relating unusual symptoms to both the signs of disorder and the pattern of vibration exposure is illustrated. Assessments of severity will vary according to the reasons for assessing the health effects of vibration, and will depend on local practice and convenience, but a way of combining evaluations of symptoms and signs is demonstrated in a staging system. Although inherently complex, the methods may assist the collection of data required to improve understanding of the effects of hand-transmitted vibration and also support a more complete reporting of the condition in those adversely affected by hand-transmitted vibration.
\end{abstract}

Key words Hand-transmitted vibration, vibration-induced white finger, hand-arm vibration syndrome, symptoms, signs. 


\section{Introduction}

Hand-transmitted vibration is associated with a variety of signs and symptoms including vascular and neurological disorders [5]. The combination of all signs and all symptoms caused by hand-transmitted vibration is called the 'hand-arm vibration syndrome', HAVS. The scope and form of all signs and symptoms caused by handtransmitted vibration are not known, and so HAVS means different things to different people - both among those affected and to those diagnosing the condition.

The vascular disorders are currently called 'vibration-induced white finger', and several systems have been defined for the classification of the severity of the vascular disorders [16, 4]). There are various neurological disorders but, because they not clearly classified, their extent and form are poorly reported and poorly understood. Like vibration-induced white finger, there are staging systems for categorising so-called sensorineural disorders caused by hand-transmitted vibration (e.g., [2]).

The principal impetus for classifying the effects of hand-transmitted vibration into 'stages' has been the need to make decisions that are dependent on the severity of the disorder - for example, deciding whether to remove a person from further use of vibratory tools or deciding what level of financial compensation is appropriate. This has led to an emphasis on judging the severity of the effects with less consideration of the precise form of the effects and how their existence is to be determined. Effort has been expended on trying to agree the severity of the effects without commensurate effort on how to identify and report the effects!

The process of quantifying a phenomenon may be usefully divided into three phases: measurement, evaluation, and assessment [8].

The measurement of the effects of hand-transmitted vibration involves converting the evidence of disorder into information that can be stored in some medium (e.g., on paper or in computers). The evidence may involve both symptoms of disorder and also signs of disorder. A symptom is an abnormality in function, appearance, or sensation that is discovered by the patient - sometimes considered to be 'subjective evidence of disease'. In medicine, a sign is considered to be any abnormality that is discovered by a physician during an examination of a patient - sometimes considered to be 'objective evidence of disease'.

The evaluation of the effects of hand-transmitted vibration requires the use of scales on which to indicate the relative or absolute severity of the effects (i.e. the symptoms 
and the signs). It may not be appropriate to assume that all signs or all symptoms are of equal importance. An evaluation procedure will yield numbers such that some characteristics of the individual effects can be seen. Evaluations may be expressed by values on an ordinal, interval scale or a ratio scale (i.e. scales on which greater values indicate greater effects). Such scales will not automatically be suitable for forming a single 'weighted' value representative of the overall severity of the potentially complex combination of symptoms and signs that were measured.

An assessment involves consideration of the evaluations of the various symptoms and signs and a judgement about them. Whereas evaluation results in values that are representative of the symptoms and signs, an assessment judges the overall outcome based on a criterion. Assessments are required for some purpose (e.g. to decide on removal from work or compensation based on current local practice) but they are not necessary for recording or monitoring the health of a patient. The use of an inappropriate scale for assessment will obscure the information needed to monitor properly a patient's health.

The boundaries between measurement, evaluation and assessment are easily and, too often, blurred. The construction of scales for assessing severity without adequately defining methods for measuring and evaluating the relevant effects allows judgements of patient health to proceed without a firm foundation, although possibly with resort to any supporting evidence to sustain the conclusion. This can happen with individual assessments and where measurement and evaluation methods can be included or excluded to reach a desired conclusion rather than being justified in their own right. In epidemiological studies, measurements and evaluations can be rejected merely because they do not correspond with assessments made on questionable scales.

The separate identification of a measurement method, an evaluation procedure, and an assessment criterion may encourage a more rigorous route to individual assessments of the hand-arm vibration syndrome, assist the collection of research evidence in epidemiological and experimental research, and contribute towards standards guiding the reporting of disorders caused by hand-transmitted vibration.

\subsection{Objectives of paper}

This paper contributes to discussion of the reporting of symptoms and signs arising from exposures to hand-transmitted vibration. The main objective is to encourage greater emphasis on the measurement and evaluation of the effects and less focus 
on assessment, which will vary according to prevailing social, political, legal, and financial considerations.

The limitations of the current system of 'staging' 'sensorineural' disorders caused by hand-transmitted vibration are reviewed and methods of reporting the various peripheral neurological symptoms and signs are suggested.

\section{Staging systems}

Over the years, many different schemes for reporting the severity of the effects of hand-transmitted vibration have been proposed [7]. Andreeva-Galanina used a fourstage classification of the severity of 'vibration disease' with much detail but broadly classifying the condition according to whether the effects were reversible, moderately marked, involved pronounced pathology, or were irreversible with a marked decrease of work capacity [1]. Drogichina and Metlina developed this into a seven-stage categorisation with seven groups of disorder caused by vibration [3]. Taylor et al. proposed a staging system for 'Raynaud's phenomenon' in which the first two stages corresponded to either tingling or numbness and stages 1 to 4 involved various amounts of finger blanching, coupled with whether the symptoms occurred in summer or winter, and the extent of social and work interference caused by the symptoms [16]. In Japan, a stage classification for peripheral vascular disorders and peripheral nervous disorders was proposed [11]. In 1987, a separation of the vascular and neurological effects in the system of Taylor et al. was proposed in the classification of vibration-induced white finger according to the 'Stockholm vascular staging system' [4] and the classification of the neurological effects of handtransmitted vibration according to the 'Stockholm sensorineural staging system' [2].

\subsection{Stockholm sensorineural staging system}

The staging system currently used for the classification of neurological disorders is referred to as the Stockholm sensorineural staging system ([2]; Table 1). Some of the shortcomings of the Stockholm staging system arise from the construction of a scale without defining the terms used within the scale (Table 2). The scale produces a result without declaring the logical steps supporting the conclusion.

The Stockholm sensorineural staging system compounds a mixture of signs and symptoms: 'numbness' and 'tingling' are symptoms whereas 'sensory perception', 'tactile discrimination' and 'manipulative dexterity' could be symptoms but are often assumed to be signs determined from the results of tests. It is not clear what type of numbness or tingling is required or how reduced sensory perception, reduced tactile 
discrimination and reduced manipulative dexterity are to be measured, or what degree of reduction is required for a positive diagnosis.

Single exposures to hand-transmitted vibration can cause temporary numbness and tingling and this can be accompanied by a period during which sensory perception and dexterity are impaired. In the extreme, therefore, it might even be considered 'normal' for persons exposed to hand-transmitted vibration to have 'intermittent or persistent numbness, reduced tactile discrimination and/or manipulative dexterity' (i.e. stage $\left.3_{S N}\right)$.

In practice, the scale is often interpreted by physicians somewhat like the Stockholm vascular scale in which the terms 'mild', 'moderate', 'severe' and 'very severe' give a clue to stages 1 to 4 . Where a disease and all relevant factors are not fully understood, the ability of a suitably experienced physician to exercise judgement may be advantageous. However, for building a foundation of knowledge, for situations where a physician is not experienced, or where physicians have differing interpretations or biases, a more structured approach is desirable.

In some countries, staging is used for deciding on financial compensation for affected workers and also the fitness for work involving exposure to hand-transmitted vibration. Where this is formulaic, it seems desirable to introduce more precision into the scale. More precision (i.e. clearly defined 'measurement' and 'evaluation' procedures) need not remove the ability of the physician to exercise discretion; it merely allows the judgement (i.e. the 'assessment') to rest on a more firm and more visible foundation.

\subsection{Separation of signs and symptoms}

To 'stage' the symptoms and signs on a single scale does not clearly indicate to what extent the result is influenced by symptoms, or signs, or both - a stage could be achieved primarily from symptoms or primarily from signs. With symptoms being questionable (if they are not considered to be accurately represented by the patient for some reason) and signs not being specific to the effects of hand-transmitted vibration, their combination into a single scale can obfuscate the evidence. It should be obvious from the stage of disease what has caused the stage - but that is not currently possible.

It would seem better to report and consider symptoms in their own right and then relate these symptoms to any evidence for disease as indicated by the signs, 
evidence of exposure to vibration, and evidence of other factors that may have caused or contributed to the symptoms.

In practice, an awareness of problems commences with symptoms and it will often be assumed that there is no problem if there are no symptoms. Tests may be capable of showing pre-symptomatic evidence of disease (e.g. elevated thresholds for perception that are not known to the patient) and this may be helpful for prevention, but currently it is not necessary to consider signs without symptoms. In the future, when the interpretation of tests is better understood, tests may be more useful than symptoms (as with hearing thresholds for detecting noise-induced hearing loss).

So the presence of symptoms currently starts the process of assessing the hand-arm vibration syndrome in a patient. The role of signs is either to seek confirmation of the symptoms, or to help identify the characteristics or severity of the disorder, or to help identify other potential causes of the disorder.

\section{Requirements for a scale of the effects of hand-transmitted vibration}

Staging systems for the hand-arm vibration syndrome refer to those symptoms and signs known at the time the scales were proposed. As understanding advances, the scope can be refined and the symptoms and signs can be redefined.

Apart from distinguishing between differing degrees of severity of disorder, the currently used staging systems have no clearly stated range of purposes for which they are considered suitable or unsuitable.

\subsection{Applications of scales for cataloguing disorders}

A scale could identify whether a symptom or sign exists, where it occurs, when it occurs, or its severity. The severity may depend on many factors, such as the extent of a symptom or sign (e.g. the areas of the body affected), the frequency with which a symptom occurs (e.g., once a year or every day), the duration of symptoms (e.g., all the time or in 5-minute attacks) and the conditions in which symptoms occur (e.g., after vibration exposure, during cold conditions).

The lack of precision in the current sensorineural staging system means it is not useful for reporting or monitoring the progression of individual signs or symptoms, other than in a very coarse manner. A better means of reporting and monitoring the known symptoms and signs would assist those trying to understand the effects of hand-transmitted vibration as well as those trying to monitor the condition in individual patients. 


\subsection{Distinction between symptoms and signs}

With current knowledge, there can be symptoms unsupported by signs from objective tests and there can be signs without symptoms. The physiological mechanisms that link the symptoms and signs of the peripheral neurological disorders caused by hand-transmitted vibration are not yet know. It therefore seems useful to catalogue separately the symptoms and signs in a manner that the differences and similarities can be observed.

\subsection{No feedback}

A scale should not contain feedback, such that the consequences of a rating are reflected in the rating. For example, removal from work might arise from a rating so it is not appropriate to define another rating as being appropriate when a worker has been removed from future vibration exposure.

\subsection{Interpretation of scales}

The terms used in the scale should be defined so that they have the same interpretation in different languages. Currently, while the words used for the symptoms are translated into many different languages they are not always interpreted in the same way. The definitions in Table 3 are used for this paper.

Currently, the most commonly used tests for detecting localised peripheral neurological disorders associated with hand-transmitted vibration are the measurement of sensory perception, manipulative dexterity, and grip force [10, 12 , 13]. The signs are therefore defined by the results of such tests, which are assumed to be applied in standardised form - the application of similarly named tests in different forms can yield different results and different conclusions.

\subsection{Completeness of knowledge}

In order to construct a fully satisfactory scale it is necessary to know the extent and characteristics of all effects of hand-transmitted vibration. Clearly, with present knowledge this is not possible. It is hoped that the ideas discussed below will stimulate the collection of the additional information needed to refine the methods over coming years.

\section{Evaluation systems}

For the assessment of vibration-induced white finger, the Stockholm workshop scale provides a means of staging the severity of the vascular effects of hand-transmitted 
vibration and is equivalent to the sensorineural staging system. In addition, a scoring system provides an evaluation of the areas affected by whiteness (Figure $1 ;[6,7]$ ). The scores correspond to areas on the digits commencing with the thumb. On the fingers a score of 1 is given for a sign or symptom on the distal phalanx, a score of 2 for a sign or symptom on the middle phalanx and a score of 3 for a sign or symptom on the proximal phalanx. On the thumbs the scores are 4 for the distal phalanx and 5 for the proximal phalanx. The right hand is recorded before the left hand because the right hand of the patient is on the left of the examiner. The scoring of vibration-induced white finger is often based on reports of blanching by the patient. Scoring can also be used to record blanching observed by another person, or that recorded photographically.

To preserve consistency, and assist comparison between neurological and vascular signs and symptoms, it seems useful to use a similar scoring system to record the locations of peripheral neurological effects of hand-transmitted vibration. An advantage of the scoring system is that it identifies the location (hand, finger, and phalanx) that is effected, whereas the Stockholm sensorineural staging system does not even identify which hand has symptoms or signs of disorder. If the same system is used for both the symptoms and the signs it is then possible to see the extent of any correspondence between the locations of the symptoms and signs. For several years, this scoring system has been used in some clinics to identify the areas of the digits reported by patients as suffering from numbness or tingling.

\subsection{Scoring neurological symptoms}

When recording symptoms it is desired to identify only those experiences of a patient that are 'unusual'. The round of daily living produces many variations in sensations and capability that are 'usual' in healthy people in some circumstances but 'unusual' in other circumstances. The identification of symptoms relevant to the diagnosis of the effects of hand-transmitted vibration should exclude those experiences that would occur even without a disorder arising from vibration exposure.

Numbness and tingling can occur without there being a neurological disorder caused by hand-transmitted vibration. These variations in sensation can arise from various different causes unrelated to vibration but also as a normal reaction to vibration. For example, tingling after exposure to hand-transmitted vibration is a normal response to vibration (similar to tinnitus, ringing in the ears after exposure to loud noise), so it seems reasonable to exclude this from a rating of the severity of the hand-arm vibration syndrome - although such tingling may provide a hint as to the 
characteristics of the vibration exposure. Similarly, tingling and numbness during and after gripping is not an abnormal response. Tingling and numbness only associated with cold may also be excluded, although this assumes that where such effects of cold are indicative of vascular problems they are recognised in the quantification of the vascular effects of hand-transmitted vibration. Tingling and numbness that only occur at night may be considered suggestive of carpal tunnel syndrome and not necessarily a consequence of hand-transmitted vibration. (It is assumed that if carpal tunnel syndrome is considered to have been caused by the use of vibratory tools it will be diagnosed and categorised separately).

Based on the above considerations, the symptoms called 'numbness' and 'tingling' would be based on what is experienced 'at other times' (i.e. without provocation from current or recent vibration, gripping, cold, attacks of finger blanching, or sleep). This may greatly reduce the number of vibration-exposed workers currently classified as having 'tingling' and 'numbness' caused by occupational exposure to handtransmitted vibration. Similar arguments may be used to filter the reporting of perceived weakness of grip, clumsiness, and pains in the fingers, hands, arms, and shoulders to problems that are 'unusual' (see Table 4).

A problem with scoring, which is common to the Stockholm sensorineural staging system, is the interpretation of what is sufficient to be considered 'unusual' (e.g. is it a current problem, and what duration, frequency and severity is required for it to be a sufficiently significant problem to be 'unusual'). With current understanding, it seems reasonable to assume that peripheral neurological symptoms arising from disorders caused by hand-transmitted vibration are fairly steady-state - not totally eliminated by changes in temperature or climate, unlike the vascular components of the handarm vibration syndrome. For example, it may be considered that if a problem (numbness, tingling, weakness of grip, finger clumsiness or pain) has not been present for more than 4 hours a day on most days of the week during the past 4 weeks then it is not indicative of a chronic disorder arising from the patient's longterm exposure to hand-transmitted vibration (see Table 4). The periods 4 hours, 4 days and 4 weeks are used for illustration and, of course, the symptom would need to have existed for more than 4 weeks for the problem to be considered a chronic disorder.

The peripheral neurological symptoms reported by users of vibratory tools are not always restricted to the fingers, so it may be helpful to define also methods of reporting any symptoms in the hands, arms, and shoulders. Table 4 shows how the existence and severity of numbness, tingling, and weakness in the hands could be 
recorded. A similar method is defined for clumsiness of the fingers. Pain is reported by users of some vibratory powered tools but there is currently no method of reporting its occurrence and so there is no understanding of how commonly it occurs. An occupational physician should consider other potential causes for any symptoms reported in the fingers, hands, arms, and shoulders.

It may be difficult to be confident about the existence and cause of minor symptoms. It therefore seems reasonable to exclude any symptoms the patient is aware of but does not consider to be a problem. To provide an indication of the extent to which the patient is concerned about a symptom, a four-point scale is defined ( $0=$ no symptoms; 1 = minor (not a problem for me); 2 = moderate (a problem for me); 3 = severe problem for me). It is suggested that the patient's perception of the severity of all symptoms is recorded (for example using subscripts as in Table 4) but that diagnosis may consider excluding symptoms the patient considers not to be a problem.

In summary, a symptom might be accepted as potentially an indication of a chronic peripheral neurological disorder caused by hand-transmitted vibration if it is 'unusual' - as indicated by a tick in a grey box associated with a question in Table 4 (i.e. the symptom must have occurred other than during or after vibration, gripping, cold, finger blanching, and at night, and must have occurred during the past 4 weeks on more than 4 days a week and for more than 4 hours a day and be considered to be a problem by the patient).

\subsection{Scoring neurological signs}

The scoring of vascular and sensorineural symptoms reflects the location of the symptoms (i.e. the affected phalanges on each digit). It would therefore be logical and helpful if the reporting of signs (as indicated by objective testing) was also associated with the locations at which the measurements are obtained. Currently the symptoms can be localised to the fingers on which they are present (if the scoring system is used) but signs are usually reported as though they apply to the whole hand, even though they may be measured on a small part of a specific finger. Any correspondence between symptoms and signs is therefore currently lost in the reporting.

The tests used to detect signs give numerical values on a variety of different scales. Vibrotactile thresholds are obtained on a ratio scale of vibration acceleration (expressed in $\mathrm{ms}^{-2}$ r.m.s.) and normal thresholds vary according to the vibration frequency at which a threshold is determined. Thermal thresholds are obtained on an 
interval scale of temperature and separate values are recorded for the perception of hot and cold. Grip force is measured on a ratio scale in Newtons. Dexterity, when evaluated using the Purdue pegboard is expressed in terms of the number of pegs moved within 30 seconds. The normal values for these tests may be expected to vary with age, gender, race, and other factors (e.g., [15, 17]). The numerical values recorded during testing should be available, but are too complex for a simple interpretation by physicians and others wanting to understand the results. It is necessary that those performing the tests indicate whether the results are 'usual' (i.e. whether they are 'normal' for a person similar to the patient who has not been exposed to hand-transmitted vibration). A simple way of presenting such information is to indicate the probability that each test result would have occurred in a population of persons not exposed to hand-transmitted vibration. Three simple categories may be sufficient: (i) no clear evidence of disorder, (ii) possible disorders, and (iii) probable disorders [12,13].

Tactile sensitivity is mostly measured only on distal phalanges - where tactile discrimination is most usually required. Measurements are not made on all three phalanges of the fingers so it is possible to replace the numeral that identifies the affected phalanges experiencing symptoms (i.e. 1, 2, and 3 - see Figure 1) by a mark (e.g. $0,+$, or $\ddagger$ ) that grades the severity of the objectively measured sign of disorder at each distal phalanx.

A score of ' 0 ' corresponds to normal (a value within one standard deviation of normal). If high values are abnormal (e.g. vibrotactile thresholds) the probability of having a value below the mean plus one standard deviation is $82 \%$ (Table 5). This assumes the data are normally distributed (a transformation may be required so that the distribution is made normal).

A score of ' + ' corresponds to 'possible disorder', defined as a value between one standard deviation and two standard deviations from normal. If high values are abnormal, the probability of a normal person having a value greater than the mean plus one standard deviation is $18 \%$.

A score of ' $¥$ ' corresponds to 'probable disorder', defined as a value greater than two standard deviations from normal. If high values are abnormal, the probability of a normal person having a value greater than the mean plus one standard deviation is $2.5 \%$.

In order to determine the scores, the measured values in a patient must be compared with normative data from a suitable control population (e.g. a population of the same 
gender and a similar age). In the examples above it is assumed that the distribution of normal values is 'normal' (i.e. Gaussian) and that the probability of abnormal results can be predicted from the mean and the standard deviation. This will not always be appropriate. The provision of suitable normal values for comparison with test results is needed for test results to be interpreted with confidence.

As an example, for vibrotactile thresholds at $31.5 \mathrm{~Hz}$, the scores of disorder on the distal phalanges of the five fingers can be written as $0+\neq \ddagger+{ } 31.5$ right and $00++0_{\mathrm{V} 31.5}$ left (the symbols + and $\ddagger$ are used here in place of numerals such as 1 and 2 merely to assist distinction between symptoms and signs). The scorning should designate the test used, here vibrotactile thresholds at $31.5 \mathrm{~Hz}$ measured on each digit (see Table 6). If measurements are not obtained on a digit, a blank (i.e. '-') should be inserted. For example, if there are no measurements on the thumb, middle or ring finger the score might be: ---- $\mathrm{V}_{\mathrm{V} 1.5}$ right and $-0--{ }_{\mathrm{V} 31.5}$ left.

Scores for grip and dexterity are obtained for a whole hand, and may be classified similarly, as in Table 6. Dexterity tests using the Purdue pegboard may also employ a test with both hands.

The restriction of the classification of the symptoms 'numbness' and 'tingling' to those symptoms that are present for all (or most) of the time, and the reporting of signs for specific digits, may be expected increase the correlation between symptoms and signs of neurological disorder. Currently, for example, a person may be categorised as having numbness because it occurs on one finger when the hands are cold, but tactile sensitivity may be measured on another finger when it is not cold.

Table 7 shows an example of a summary report of all symptoms and signs from a patient. The report might be shortened if it is decided not to include some of the symptoms or signs, or it might be extended for other symptoms or signs.

\subsection{Scoring vibration exposure}

With many vibratory tools the vibration is not uniformly distributed over all fingers or equally to both hands. If one hand is not exposed, it would not be expected to show symptoms or signs caused by hand-transmitted vibration. Similarly, the fingers that are most exposed may be more at risk.

With the scoring systems allowing the localisation of the symptoms and signs, it seems helpful to use the same scheme to report variations in the vibration exposure between the ten fingers. The simplest scheme is to use that employed for the symptoms (blanching, numbness, and tingling) to identify the locations experiencing 
vibration and append a letter (i.e. 'V') to indicate that it refers to vibration and not symptoms (i.e., $03663 \vee$ right $01100_{v}$ left). Ratings are not intended to be more than a rough indication of the distribution of vibration exposure across the digits - possibly based on the patient's opinion. In many cases, there will be exposure from more than one tool to consider and, in some, cases there may be exposure other than to the hands and fingers.

\section{Application of the scores}

\subsection{Health surveillance}

As with finger blanching scores, the peripheral neurological scores for symptoms and signs give more detail than the Stockholm staging system, allowing closer observation of any progression or regression of symptoms and signs during health surveillance.

The measurements and evaluations required for scoring are possible without the clinical judgement of physicians needed for the Stockholm staging systems. The scores can assist physicians who may exercise judgement in the assessment of the signs and symptoms and decide on recommendations for action after taking into account other information, including other potential causes of the symptoms and signs.

When forming a judgement, physicians should compare the symptom scores and sign scores to see the correspondence between symptoms and signs. The neurological symptoms can also be compared with finger blanching scores, the results of vascular tests on individual fingers, and the pattern of vibration exposure over the fingers.

The scores may be entered into a database to assist the monitoring of patients over time. Although the presentation of data in Table 7 may appear complex, this is a characteristic of the hand-arm vibration syndrome - a simpler presentation would be more difficult to understand since it would combine the underlying data and be less transparent. However, it may not always be considered appropriate to obtain all the information implied by Table 7: the overall scheme is defined here as a consistent set of tools that can be used if they are needed.

\subsection{The probability of an abnormal test result}

When conducting objective tests, some abnormal results will occur by chance: the greater the number of tests, the greater the chances of an abnormal result. As the 
number of tests increases, so the criterion for accepting abnormality should also increase. For example, if normal results are distributed according to a normal distribution, the probability of exceeding the mean plus one standard deviation with one test is similar to the probability of exceeding the mean plus two standard deviations when using eight tests.

A different number of tests will be performed in different circumstances and so a simple summary of the test results (as in Table 7) should not be influenced by the number of tests performed. However, the assessment of the evidence by a competent person should recognise that increasing the number of tests (e.g. testing more fingers) is likely to increase the number of abnormal results. Within specific schemes for diagnosing disorders it will be possible to define the number of tests to be performed and adjust the criteria accordingly. Undue weight should not be given to a positive test result if very many tests have been performed and most are normal.

\subsection{Diagnosis}

The diagnosis of disorders caused by hand-transmitted vibration is potentially complex, requiring consideration of many factors additional to a report of the patient's symptoms and the results of tests. Even so, many users of vibratory tools are currently diagnosed from a report of their symptoms, a history of vibration exposure, and the absence of any obvious alternative explanation for their reported symptoms.

The example system for cataloguing symptoms and the results of tests may assist the process of filtering those exposed to hand-transmitted vibration so that greatest attention is given to those most needing the attention of physicians. Using the evaluation methods, they should be able to see smaller changes in symptoms and signs than is possible when using a staging system. In addition, occupational physicians may recommend restrictions to future exposures to vibration, provide advice to employers, and give evidence to the courts.

\subsection{Restrictions to future vibration exposures}

Assessments (e.g. ratings on a staging system) might be used to restrict future exposures to hand-transmitted vibration. For example, some have suggested that exposures to hand-transmitted vibration should be restricted so that the consequences do not progress beyond a particular stage (e.g. stage 2). This seems unsatisfactory (even if the staging system is a well defined, sensitive, and specific indicator of disease), since it assumes that there is an acceptable extent of disease. 
The evaluation of symptoms and signs can guide whether a vibration-induced disorder exists and, if so, the conditions that caused them. If vibration has caused a disorder it is reasonable to assume that continued exposure to similar vibration may result in progression of the disorder in the affected person and others who are exposed similarly. Prevention should seek to prevent the progression of a disorder, so a person with a vibration-induced disorder should not continue to be exposed to conditions that caused the disorder without changes to reduce the risk sufficiently to expect that there will not be further progression of the disorder. If subsequent reevaluation reveals that there has been progression of symptoms or signs it indicates that there has been insufficient reduction of risk and further preventative measures will be needed, ultimately the elimination of vibration exposure.

The suggested scoring of symptoms and signs allows a clearer view of any progression of symptoms and signs than a coarse staging, and should assist the implementation of earlier preventative measures appropriate to the risks in individuals.

\subsection{Compensation}

Schemes for compensating those with vibration-induced disorders vary from country to country. The schemes include state compensation for specific disorders related to, or independent of, the cause, and also compensation where there has been negligence [9].

When compensating for the consequences of exposures to hand-transmitted vibration it is useful to distinguish between the disease (i.e. physiological changes induced by the vibration), the impairment in function arising from the disease (e.g. reduced sense of touch), the consequent handicap (preventing the performance of a range of possible activities), and any resulting disability (e.g. inability to perform a specific job and reduced earning ability) (see Figure 2). The scoring schemes defined here, and the Stockholm sensorineural staging system, reflect the signs but do little to identify the handicap or disability in an individual. It is the disability caused by the hand-arm vibration syndrome that has the greatest effect on the individual and should therefore influence any compensation.

Disability depends on the impact of disease on the current and future employment of individuals and their leisure activities. Because disability depends on factors that change over time and between individuals, it is important that disability does not influence the scoring of sensorineural disorders. The disorders should be determined 
and reported and then related to the disability of the individual depending on their work, leisure activities, and other personal factors.

\subsection{Composite scores}

It may be tempting to aggregate the scores for individual signs and symptoms to form a single composite score indicating the degree of disorder in an individual as a result of hand-transmitted vibration. This has various dangers.

The greatest problem is that an aggregate score conceals the information that the scores are designed to provide. The individual scores for symptoms and signs are a signature of the disorder. The validity of the signature is apparent in the individual scores, but not in a composite score. The scores for each symptom and each sign are therefore more useful than an aggregate when seeking to understand the disease in an individual.

Composite scores have been proposed for deciding on compensation payments to large numbers of workers where there are insufficient resources to consider individuals. Such schemes are unlikely to pass the scrutiny of time since any aggregate is merely a convenient combination of what those involved choose to aggregate. There is no combination of indicators of symptoms and signs by a composite score that is likely to be a good indicator of disability in individuals.

A composite score will not be necessary if an appropriate scale of assessment (e.g. staging) is derived from a combined consideration of the symptoms and signs of disorder

\section{The assessment of peripheral neurological disorders}

The purpose of staging the hand-arm vibration syndrome is to provide an assessment of the severity of one or more consequences of exposure to handtransmitted vibration.

Vibration-exposed workers trying to give factual accounts of their symptoms can misunderstand and accidentally exaggerate or belittle their problems. Staging based solely on symptoms is also vulnerable to deliberately false claims and deliberately false denials - where there is the potential for gaining compensation or losing a job, workers may be inclined to exaggerate or belittle the problem.

Objective tests are not yet a sufficient means of confirming the existence, the severity, and the cause of all relevant peripheral neurological symptoms. Some tests (e.g. elevated tactile thresholds) show evidence of dysfunction in vibration-exposed 
persons that appear to correlate with some symptoms and are considered sufficiently useful to compliment the reporting of symptoms, but alone they do not prove the existence of the hand-arm vibration syndrome.

The severity of specific symptoms and signs is better reflected in the scoring systems proposed above than in a staging system. So although staging could be based on either symptoms or signs, if the scores for symptoms and the results of objective tests are reported in raw form, staging may be most useful when it takes into account both symptoms and signs. Many different staging systems could be designed to provide simple composite scales of selected combinations of symptoms and signs.

It seems reasonable that the assessment of the severity of the condition should be based on the symptoms so long as there is sufficient supporting evidence to expect such symptoms from the results of suitable tests - such as an appropriate sign of probable dysfunction at a location where the patient reports a relevant symptom. One example of such a staging system is shown in Table 8.

With current limitations to understanding of the relation between symptoms and signs, it seems appropriate to allow some flexibility in a staging system. As knowledge advances and the tests are improved, it should be possible to be more specific as to which signs corroborate which symptoms.

When based on the methods of measuring and evaluating symptoms and signs described above, a staging system such as that in Table 8 makes it clear what problems exist at each stage. It is possible for non-medical persons to understand the scale and also possible for those other than physicians to anticipate the stage appropriate to an individual. However, staging will normally be the responsibility an occupational physician because the role of the work and the work environment of the individual and the possibility of other causes for the symptoms and signs should be considered.

The example staging system in Table 8 assumes a worker is prepared to admit to having symptoms. Some patients may prefer not to admit for fear of loosing their jobs. Where the results of tests clearly indicate a probable disorder this should be taken into account in the management of the patient. Similarly, if a worker reports symptoms without supporting evidence in the form of relevant signs, the occupational physician should record the evidence and use professional judgement based on other evidence as to how to proceed.

Some may prefer a staging system that solely reflects a physician's view of the importance of the disorder to the patient - perhaps on a scale from 0 to 4 . Without 
the regular 'calibration' of all physicians, such a scale is likely to contribute more to disagreement and court appearances than to any advance in understanding. Nevertheless, it should be recognised that the impact of disease on an individual is not well reflected by a single composite measure of symptoms and signs - the proficient dart thrower, the guitar and piano player, the fisherman and the model maker, may be more greatly affected by a specific degree of peripheral neurological disorder than the television viewer.

\section{Equivalent vascular staging system}

The system for staging peripheral neurological disorders caused by hand-transmitted vibration in Table 8 is based on relevant symptoms supported by evidence of relevant disorder. The same approach can be used when assessing the stages of vibration-induced white finger, although this is not the philosophy behind the currently used Stockholm workshop vascular scale (Table 9).

The predominant symptom of vibration-induced white finger is attacks of clearly demarcated finger blanching generally provoked by cold [5]. Sufficient evidence could be the observation of an attack by a suitably qualified physician, but very few physicians observe blanching attacks in patients. It may be considered sufficient for some other persons to be independent witnesses of attacks, or suitably verified photographs showing both hands and face might be accepted.

The evidence of vibration-induced white finger may alternatively take the form of a sign of probable disorder as indicated by an accepted test (e.g. reduced finger systolic blood pressures during cold or prolonged re-warming times after cold provocation). Such tests would need to be performed in standardised conditions and the relevant criterion for a probable disorder may need to take into account the age and gender of the patient.

In the event that a person claiming to have symptoms is unable to obtain 'acceptable evidence' of finger blanching there must be doubt as to whether the symptoms are correctly understood and described by the patient. However, patient symptoms are important - they should be recorded and an occupational physician should provide appropriate advice on patient management based on all the available information.

Attacks of vibration-induced white finger arise from abnormal response to cold. It seems likely that abnormal responses to cold occur before the first attack of finger blanching - and may explain the 'cold fingers' often reported among users of vibratory tools. Similar to recording numbness and tingling, it may be appropriate to 
record the development of unusual 'cold fingers' as this may explain otherwise apparently false positive results of vascular tests and warn of the potential for the development of attacks of clearly demarcated finger blanching currently required for a diagnosis of vibration-induced white finger.

Table 10 shows an example staging system for vibration-induced white finger using the same principles adopted for the staging of peripheral neurological disorders in Table 8. However, similar to the staging of peripheral neurological disorders, the staging of vascular disorders requires the development of more precise definitions of how to measure and evaluate the relevant signs and symptoms [14].

\section{Discussion}

The categorisation of symptoms and signs presented here may seem complex, but this is an inevitable consequence of the apparently complex and diverse consequences of exposures to hand-transmitted vibration. Forcing the complex pattern to be simple will conceal features that are the signature of the disease and will blur changes that can indicate progression of disease.

The examples of the procedure have been restricted to frequently reported effects of hand-transmitted vibration in the upper limbs. Other symptoms are sometimes reported and many other tests can be used to investigate the effects of handtransmitted vibration. As there are advances in understanding of the effects of handtransmitted vibration and the underlying mechanisms causing the symptoms and signs, it will be appropriate to develop the systems for measuring, evaluating, and assessing the effects of hand-transmitted vibration considered here.

The peripheral neurological effects of vibration may not be restricted to the upper limbs. Similar vibration of the lower limbs may be expected to produce similar effects. Vibration of other parts of the body, either by direct application of vibration to those parts or as a result of the transmission of vibration from other locations, may have the potential to cause injury to those parts. The system described here is restricted to the peripheral neurological effects of hand-transmitted vibration, but a similar philosophy may be appropriate at other locations.

The means of collecting the relevant information (i.e. measuring and evaluating the symptoms and signs) may be undertaken by many suitably trained persons. The tabulated result may then assist a suitably qualified and experienced occupational physician to assess the severity of the disorder and make recommendations for the management of the patient. The tabulated information should also assist the 
monitoring of patients over time and considerations related to continued exposure to vibration and compensation.

This paper primarily seeks to provide a means of reporting the symptoms and signs arising from exposures to hand-transmitted vibration. It is suggested that reports should consist of the evaluations arising from clearly defined methods of measurement. The evaluations of symptoms and signs can be combined in many ways to provide apparently simple scales of the extent of disorder. In such combined scales it currently seems appropriate to use the signs to confirm the symptoms, but when the aetiologies of the diseases caused by hand-transmitted vibration are better understood, the signs may be used with greater confidence to identify the existence of disorder and its importance. Generally, scales of assessment (e.g. staging systems) are only meaningful when the reasons for, and scope of, the assessment is defined. Without a clearly defined purpose, staging seems to be unnecessary, and possibly unhelpful.

\section{Conclusions}

Current systems for staging the effects of hand-transmitted vibration are not related to defined methods of measuring or evaluating the symptoms or the signs. Staging could be a means of assessing a patient (except that the assessment criteria have not been defined for current staging systems) or it could be a simple way of combining the effects (both symptoms and signs) on a simple scale.

The 'measurement' and the 'evaluation' of symptoms and signs arising from exposures to hand-transmitted vibration are required during health surveillance. They are also required when collecting epidemiological data for research into the effects of hand-transmitted vibration. This paper identifies methods of reporting the evaluations of symptoms and signs of peripheral neurological disorders.

A single 'assessment' (e.g. staging) of the overall effects of hand-transmitted vibration is not essential when monitoring patient health or performing epidemiological research. When judging the outcome from vibration exposure according to a specific criterion (e.g., to decide on removal from work or compensation) an assessment is required, but it should be recognised that a scale devised for this purpose is likely to vary according to the prevailing social, political and economic climate and it will not provide the detail desirable for either health surveillance or epidemiological research. 
A crude method of assessing the extent of the principal symptoms and the degree to which they are supported by relevant signs of disorder may be useful, and examples are provided for both neurological and vascular effects of hand-transmitted vibration. Such example scales provide only one of many possible perspectives on the development of disorder, but higher values correspond to both greater symptoms and greater confirmation of symptoms from the signs of disorder. Other forms of assessment may sometimes be more appropriate, especially when considering the disability of an individual arising from exposure to hand-transmitted vibration.

Separating the measurement and the evaluation of disorders from their assessment according to prevailing criteria may encourage a more rigorous route to individual assessments and improve the reporting of disorders caused by hand-transmitted vibration.

\section{Acknowledgements}

This research was supported by the European Commission under the Quality of Life and Management of Living Resources programme, project no. QLK4-2002-02650 (VIBRISKS). 


\section{References}

1. Andreeva-Galanina Y TS. (1956) Vibration and its significance in labour hygiene. Published: Leningrad.

2. Brammer AJ, Taylor W, Lundborg G. (1987) Sensorineural stages of the handarm vibration syndrome. Scandinavian Journal of Work, Environment and Health, 13, (4), 279-283.

3. Drogichina EA, Metlina NB. (1967). A contribution to the vibration disease classification. Gigiena Truda i Professional'nye Zabolevanija, 12, (5), 27-31.

4. Gemne G, Pyykko I, Taylor W, Pelmear P. (1987) The Stockholm Workshop scale for the classification of cold-induced Raynaud's phenomenon in the handarm vibration syndrome (revision of the Taylor-Pelmear scale). Scandinavian Journal of Work, Environment and Health, 13, (4), 275-278.

5. Griffin MJ, Bovenzi M. (2002) The diagnosis of disorders caused by handtransmitted vibration: Southampton Workshop 2000. International Archives of Occupational and Environmental Health 2002; 75:1-5.

6. Griffin MJ. (1982) The effects of vibration on health. Institute of Sound and Vibration Research Memorandum 632, University of Southampton.

7. Griffin MJ. (1990) Handbook of human vibration. Published: Academic Press, London, ISBN: 0-12-303040-4.

8. Griffin MJ. (1997) Measurement, evaluation, and assessment of occupational exposures to hand-transmitted vibration. Occupational and Environmental Medicine, 54, (2), 73-89.

9. Griffin MJ. (2007) Negligent exposures to hand-transmitted vibration. International Archives of Occupational and Environmental Health, (awaiting publication).

10. International Organization for Standardization (2001) Mechanical vibration vibrotactile perception thresholds for the assessment of nerve dysfunction - Part 1: Methods of measurement at the fingertips. International Standard, ISO 13091$1 ; 2001(E)$. 
11. Ishida K, Ishida H, Ohno T, Saito K, Nasu Y, Habu K, Matoba T, Mishima Y. (1986) Report of the Ad Hoc Committee on Treatment of Vibration Disease, Pub: Labor Standards Bureau of the Ministry of Labor, Japan.

12. Lindsell CJ, Griffin MJ. (1998) Standardised diagnostic methods for assessing components of the hand-arm vibration syndrome. HSE Books, 1998, CRR197/1998, ISBN 0717616401.

13. Lindsell CJ, Griffin MJ. (2002) Normative data for vascular and neurological tests of the hand-arm vibration syndrome. International Archives of Occupational and Environmental Health, 75, (1-2), 43-54.

14. Palmer KT, Coggon DN. (1997) Deficiencies of the Stockholm vascular grading scale for hand-arm vibration. Scandinavian Journal of Work, Environment and Health, 23, (6), 435-439.

15. Seah S-A, Griffin MJ. (2007) Normal values for thermotactile and vibrotactile thresholds in males and females. International Archives of Occupational and Environmental Health, (awaiting publication).

16. Taylor W, Pelmear PL, Pearson J. (1974) Raynaud's phenomenon in forestry chain saw operators. In: The Vibration Syndrome, Proc. of a Conference on the Medical Engineering and Legal Aspects of Hand-Arm Vibration, at the University of Dundee, 12-14 July, 1972, Edited: W. Taylor, Published: Academic Press, ISBN 012684760 6, 121-139.

17. Welsh AJL, Griffin MJ. (2007) Normal values for finger systolic blood pressures in males and females. International Archives of Occupational and Environmental Health, (awaiting publication). 
Table 1 Stockholm 'sensorineural stages' of the effects of hand-transmitted vibration [2].

\begin{tabular}{|c|l|}
\hline Stage & \multicolumn{1}{|c|}{ Symptoms } \\
\hline $0_{\mathrm{SN}}$ & Exposed to vibration but no symptoms \\
\hline $1_{\mathrm{SN}}$ & Intermittent numbness with or without tingling \\
\hline $2_{\mathrm{SN}}$ & Intermittent or persistent numbness, reduced sensory perception \\
\hline $3_{\mathrm{SN}}$ & $\begin{array}{l}\text { Intermittent or persistent numbness, reduced tactile discrimination } \\
\text { and/or manipulative dexterity }\end{array}$ \\
\hline
\end{tabular}


Table 2 Some limitations in the Stockholm sensorineural staging system

\begin{tabular}{|c|c|}
\hline & Problems \\
\hline \multirow[t]{2}{*}{ Undefined symptoms } & Numbness \\
\hline & Tingling \\
\hline \multirow[t]{4}{*}{ Undefined signs } & Sensory perception \\
\hline & Tactile discrimination \\
\hline & Manipulative dexterity \\
\hline & $\begin{array}{l}\text { No distinction between 'sensory perception' and 'tactile } \\
\text { discrimination' }\end{array}$ \\
\hline \multirow[t]{3}{*}{ Undefined adjectives } & Intermittent \\
\hline & Persistent \\
\hline & Reduced \\
\hline \multirow[t]{4}{*}{ Other problems } & Unclear distinction between 'intermittent' and 'persistent'. \\
\hline & An unclear mix of symptoms and signs \\
\hline & $\begin{array}{l}\text { The stage of disease does not uniquely indicate either the } \\
\text { signs or symptoms present. }\end{array}$ \\
\hline & The stage does not indicate patient disability. \\
\hline
\end{tabular}


Table 3 Definitions of symptoms associated with disorders arising from handtransmitted vibration

\begin{tabular}{|l|l|}
\hline \multicolumn{1}{|c|}{ Symptom } & \multicolumn{1}{c|}{ Definition } \\
\hline Numbness & $\begin{array}{l}\text { A sensation associated with impaired cutaneous } \\
\text { perception. }\end{array}$ \\
\hline Tingling & $\begin{array}{l}\text { A prickling sensation (similar to that caused by emotion, } \\
\text { striking a nerve, changes in temperature, exposure to } \\
\text { vibration, etc.). }\end{array}$ \\
\hline $\begin{array}{l}\text { Weakness } \\
\text { of grip }\end{array}$ & $\begin{array}{l}\text { A feeling that hand grip force is less than it should be or } \\
\text { that hand grip is likely to fail. }\end{array}$ \\
\hline $\begin{array}{l}\text { Clumsiness } \\
\text { in the fingers }\end{array}$ & $\begin{array}{l}\text { A feeling that moving or handling things with the fingers is } \\
\text { more awkward or less precise than it should be. }\end{array}$ \\
\hline Pain & $\begin{array}{l}\text { An unpleasant sensory experience associated with, or } \\
\text { described in terms of, actual or potential tissue damage. }\end{array}$ \\
\hline
\end{tabular}


Table 4 Reporting unusual symptoms of peripheral neurological disorders associated with handtransmitted vibration (scores represent areas of digits affected, and are included as examples)

\begin{tabular}{|c|c|c|c|c|c|}
\hline & $\underset{\mathrm{N}}{\text { Numbness }}$ & $\underset{T}{\text { Tingling }}$ & $\underset{W}{\text { Weakness }}$ & $\begin{array}{c}\text { Clumsiness } \\
\text { C }\end{array}$ & $\begin{array}{l}\text { Pain } \\
\text { P }\end{array}$ \\
\hline & $x$ or $\checkmark$ & $x$ or $\checkmark$ & $x$ or $\checkmark$ & $x$ or $\checkmark$ & $x$ or $\checkmark$ \\
\hline \multicolumn{6}{|l|}{ 1. Ever experienced } \\
\hline \multicolumn{6}{|l|}{ 2. Provocation: } \\
\hline \multicolumn{6}{|l|}{ During or after vibration } \\
\hline \multicolumn{6}{|l|}{ During or after gripping } \\
\hline \multicolumn{6}{|l|}{ During or after cold } \\
\hline \multicolumn{6}{|l|}{$\begin{array}{r}\text { During or after finger } \\
\text { blanching }\end{array}$} \\
\hline \multicolumn{6}{|l|}{ At night } \\
\hline \multicolumn{6}{|l|}{ At other times } \\
\hline \multicolumn{6}{|l|}{ 3. Present in past 4 weeks } \\
\hline \multicolumn{6}{|l|}{ 4. Frequency in past year: } \\
\hline \multicolumn{6}{|l|}{$<4$ days per year } \\
\hline \multicolumn{6}{|l|}{ Usually $<4$ days per month } \\
\hline \multicolumn{6}{|l|}{ Usually $<4$ days per week } \\
\hline \multicolumn{6}{|l|}{ Usually $\geq 4$ days per week } \\
\hline \multicolumn{6}{|c|}{ 5. Duration of symptoms on days present: } \\
\hline \multicolumn{6}{|c|}{ Usually $<1 / 4$ hour/day } \\
\hline \multicolumn{6}{|l|}{ Usually $<1$ hours/day } \\
\hline \multicolumn{6}{|l|}{ Usually $<4$ hours/day } \\
\hline \multicolumn{6}{|l|}{ Usually $\geq 4$ hours per day } \\
\hline \multicolumn{6}{|l|}{ 6. Severity of symptoms: } \\
\hline None & 0 & 0 & 0 & 0 & 0 \\
\hline Minor (not a problem for me) & 1 & 1 & 1 & 1 & 1 \\
\hline Moderate (a problem for me) & 2 & 2 & 2 & 2 & 2 \\
\hline Severe problem for me & 3 & 3 & 3 & 3 & 3 \\
\hline \multicolumn{6}{|c|}{ 7. Score areas reported affected by symptoms (examples shown): } \\
\hline Right fingers & $03663_{N 3 \text { right }}$ & 03333 $3_{\mathrm{T} 2 \text { right }}$ & - & $\mathrm{F}_{\mathrm{C} 1 \text { right }}$ & $\mathrm{F}_{\mathrm{P} 1 \text { right }}$ \\
\hline Left fingers & $01100_{\mathrm{N} 1 \text { left }}$ & $00010_{\text {T1 left }}$ & - & $\mathrm{F}_{\mathrm{C} 1 \text { left }}$ & $F_{\mathrm{PO} \text { left }}$ \\
\hline Hands & $\mathrm{H}_{\mathrm{N} 0 \text { right } \mathrm{N} 2 \text { left }}$ & $\mathrm{H}_{\text {TO right T2 left }}$ & $\mathrm{H}_{\text {wo right w2 left }}$ & - & $\mathrm{H}_{\mathrm{P} 1 \text { right } \mathrm{P} 2 \text { left }}$ \\
\hline Arms & - & - & - & - & AP0 right P2 left \\
\hline Shoulders & - & - & - & - & $\mathrm{S}_{\mathrm{P} 2 \text { right } \mathrm{P2} \text { left }}$ \\
\hline \multicolumn{6}{|c|}{ 8. Symptom significant and "unusual"? } \\
\hline \multicolumn{6}{|l|}{ (i.e. $\checkmark$ in grey boxes above) } \\
\hline \multicolumn{6}{|l|}{ 9. Dates: } \\
\hline \multicolumn{6}{|l|}{ Unusual symptom first noticed: } \\
\hline First exposed to vibration: & & & & & \\
\hline $\begin{array}{l}\text { 'Tick' if first exposed before } \\
\text { symptom first noticed: }\end{array}$ & & & & & \\
\hline 10. No other medical explana & on for unuse & al symptom & & & \\
\hline 'Tick' if no other explanation: & & & & & \\
\hline 11. Vibration caused or contr & outed to 'sigr & ificant unus & ual symptom & & \\
\hline 'Tick' if probable HAVS: & & & & & \\
\hline
\end{tabular}


Table 5 Classification of a sign as reflecting normal response, possible disorder, or probable disorder, based on a suitable test (percentages assume the distribution of values is normal, after transformation if necessary).

\begin{tabular}{|l|l|c|}
\hline & \multicolumn{1}{|c|}{ Objective test result } & $\begin{array}{c}\text { Probability of } \\
\text { false positive } \\
\text { diagnosis }\end{array}$ \\
\hline Normal & $<$ Mean +1 standard deviation & - \\
\hline Possible disorder & $>$ Mean +1 standard deviation & $18 \%$ \\
\hline Probable disorder & $>$ Mean +2 standard deviations & $2.5 \%$ \\
\hline
\end{tabular}


Table 6 Reporting the signs of sensorineural disorders associated with handtransmitted vibration (example scores represent severity on each digit)

\begin{tabular}{|c|c|c|}
\hline Sign & $\begin{array}{l}\text { Reporting of test } \\
\text { result }\end{array}$ & $\begin{array}{l}\text { Scoring of signs } \\
\text { (example) }\end{array}$ \\
\hline \multirow[t]{2}{*}{ Vibrotactile thresholds } & $\begin{array}{l}\text { Measured thresholds } \\
\text { (on distal phalanges) }\end{array}$ & $\begin{array}{l}0+\ddagger \ddagger+\text { v31.5 right } \\
00++0 \text { v31.5 left }\end{array}$ \\
\hline & $\begin{array}{l}\text { Measured thresholds } \\
\text { (on distal phalanges) }\end{array}$ & $\begin{array}{l}0+\ddagger \ddagger+v 125 \text { right } \\
00++0_{\text {v125 left }}\end{array}$ \\
\hline \multirow[t]{2}{*}{ Thermotactile thresholds } & $\begin{array}{l}\text { Measured thresholds } \\
\text { (on distal phalanges) }\end{array}$ & $\begin{array}{l}++\ddagger+0{ }_{\text {TH right }} \\
0+00+_{\text {TH left }}\end{array}$ \\
\hline & $\begin{array}{l}\text { Measured thresholds } \\
\text { (on distal phalanges) }\end{array}$ & $\begin{array}{l}++\ddagger+0 \text { TC right } \\
0+00+{ }_{\text {TC left }}\end{array}$ \\
\hline Grip force & $\begin{array}{l}\text { Measured force } \\
\text { ( } 2 \text { hands) }\end{array}$ & $\begin{array}{l}\ddagger \text { GRIP right } \\
+ \text { GRIP left }\end{array}$ \\
\hline Dexterity & $\begin{array}{l}\text { Measured dexterity } \\
\text { ( } 2 \text { hands) }\end{array}$ & $\begin{array}{l}+ \text { DEXTERITY right } \\
0 \text { DEXTERITY left } \\
\ddagger \text { DEXTERITY both }\end{array}$ \\
\hline Other & $\begin{array}{l}\text { (Define test, norma } \\
\text { findings) }\end{array}$ & values and record \\
\hline \multicolumn{3}{|c|}{$\begin{array}{l}0 \text { : finger (or hand) tested with normal result } \\
+: \text { finger (or hand) with possible disorder (i.e. >mean }+1 S \mathrm{SD} \text { ) } \\
\ddagger \text { : finger (or hand) with probable disorder (i.e. >mean }+2 \text { SD) } \\
-: \text { finger (or hand) not tested. }\end{array}$} \\
\hline \multicolumn{3}{|c|}{$\begin{array}{l}\text { Subscript key: } \\
\text { V31.5 right: vibrotactile threshold at } 31.5 \mathrm{~Hz} \text { on the right hand } \\
\text { V125 left: vibrotactile threshold at } 125 \mathrm{~Hz} \text { on the left hand } \\
\text { TH right: thermal thresholds for heat on the right hand } \\
\text { TC left: thermal thresholds for cold on the left hand }\end{array}$} \\
\hline
\end{tabular}


Table 7 Summary report of symptoms and signs of sensorineural disorders associated with hand-transmitted vibration (example).

\begin{tabular}{|c|c|c|}
\hline & Right & Left \\
\hline \multicolumn{3}{|l|}{ Symptoms: } \\
\hline Unusual finger numbness score & $03663_{\mathrm{N} 3}$ & $01100_{\mathrm{N} 1}$ \\
\hline Unusual finger tingling score & $03333_{\mathrm{T} 2}$ & $00010_{T 1}$ \\
\hline Finger clumsiness & 1 & 2 \\
\hline Weakness of grip & 0 & 2 \\
\hline $\begin{array}{r}\text { Finger pain } \\
\text { Hand pain } \\
\text { Arm pain } \\
\text { Shoulder pain }\end{array}$ & $\begin{array}{l}1 \\
1 \\
0 \\
2\end{array}$ & $\begin{array}{l}0 \\
2 \\
2 \\
2\end{array}$ \\
\hline \multicolumn{3}{|l|}{ Signs: } \\
\hline $\begin{array}{r}\text { Vibrotactile thresholds: } 31.5 \mathrm{~Hz} \\
125 \mathrm{~Hz}\end{array}$ & $\begin{array}{l}0+ \pm \pm+ \\
0+\ddagger \ddagger+\end{array}$ & $\begin{array}{l}00++0 \\
00++0\end{array}$ \\
\hline $\begin{array}{r}\text { Thermotactile thresholds: hot } \\
\text { cold }\end{array}$ & $\begin{array}{l}++\ddagger+0 \\
++\ddagger+0\end{array}$ & $\begin{array}{l}0+00+ \\
0+00+\end{array}$ \\
\hline Grip force & $\ddagger$ & + \\
\hline Dexterity & + & 0 \\
\hline \multicolumn{3}{|l|}{ Vibration exposure: } \\
\hline Location of contact with vibration & $23221_{V \text { right }}$ & $01123_{V_{\text {left }}}$ \\
\hline \multicolumn{3}{|c|}{$\begin{array}{l}\text { Finger numbness and tingling: } \\
\text { Finger scores: } 0=\text { none; } 1=\text { distal phalanx; } 2=\text { middle phalanx; } 3= \\
\text { proximal phalanx; (on thumb: } 4=\text { distal phalanx; } 5=\text { proximal phalanx). }\end{array}$} \\
\hline \multicolumn{3}{|c|}{$\begin{array}{l}\text { Subscript: } N=\text { numbness; } \mathrm{T}=\text { tingling; severity: } 0=\text { none; } 1=\text { minor } ; 2= \\
\text { moderate; } 3=\text { severe. }\end{array}$} \\
\hline \multicolumn{3}{|c|}{$\begin{array}{l}\text { Clumsiness and weakness : } \\
\text { Severity: } 0=\text { none } ; 1=\text { minor } ; 2=\text { moderate } ; 3=\text { severe }\end{array}$} \\
\hline \multicolumn{3}{|c|}{$\begin{array}{l}\text { Pain: } \\
\text { Severity: } 0=\text { none; } 1 \text { = minor } ; 2=\text { moderate } ; 3=\text { severe } .\end{array}$} \\
\hline \multicolumn{3}{|l|}{ Sign key: } \\
\hline \multicolumn{3}{|c|}{$\begin{array}{l}0 \text { : finger (or hand) tested with normal result } \\
+: \text { finger (or hand) with possible disorder (i.e. >mean }+1 \text { SD) } \\
\ddagger \text { :finger (or hand) with probable disorder (i.e. >mean + } 2 \text { SD) } \\
-\quad: \text { finger (or hand) not tested) }\end{array}$} \\
\hline \multicolumn{3}{|l|}{ Vibration exposure key: } \\
\hline $\begin{array}{l}0=\text { little or no direct contact with vibration; } \\
\text { moderate exposure; } 3=\text { most exposure. }\end{array}$ & east ex & \\
\hline
\end{tabular}


Table 8 Example of the combined use of symptoms and signs to define 'peripheral neurological' stages of the effects of hand-transmitted vibration. The peripheral neurological stages for the left and right hands may be reported separately (e.g. $2_{\mathrm{PN}-\mathrm{L}} 1_{\mathrm{PN}-\mathrm{R}}$ ).

\begin{tabular}{|c|c|}
\hline Stage & Sym \\
\hline $\mathrm{O}_{\mathrm{PN}}$ & Exposed to vibration but no currer \\
\hline $\mathrm{PI}$ & $\begin{array}{l}\text { 'Unusual' numbness, or 'unusual' tingling (i.e. finger numbness or tingling score }>0 \text { ) on } 1 \\
\text { finger of either hand } \\
\text { and } \\
\text { a sign of probable disorder in the symptomatic finger (e.g., probable disorder indicated by } \\
\text { either: (i) vibrotactile perception, or (ii) thermotactile perception). }\end{array}$ \\
\hline $2 \mathrm{PN}$ & $\begin{array}{l}\text { 'Unusual' numbness, or 'unusual' tingling (i.e. finger numbness or tingling score }>0 \text { ) on } 2 \\
\text { fingers of either hand } \\
\text { and } \\
\text { a sign of probable disorder in the symptomatic fingers (e.g., probable disorder indicated } \\
\text { by either: (i) vibrotactile perception, or (ii) thermotactile perception). }\end{array}$ \\
\hline $33_{\mathrm{PN}}$ & $\begin{array}{l}\text { 'Unusual' numbness, or 'unusual' tingling (i.e. finger numbness or tingling score }>0 \text { ) on } 3 \\
\text { fingers of either hand } \\
\text { and } \\
\text { a sign of probable disorder in the symptomatic fingers (e.g., probable disorder indicated } \\
\text { by either: (i) vibrotactile perception, or (ii) thermotactile perception). }\end{array}$ \\
\hline $4_{\mathrm{PN}}$ & $\begin{array}{l}\text { 'Unusual' numbness, or 'unusual' tingling (i.e. finger numbness or tingling score }>0 \text { ) on } 4 \\
\text { fingers of either hand } \\
\text { and } \\
\text { a sign of probable disorder in the symptomatic fingers (e.g., probable disorder indicated } \\
\text { by either: (i) vibrotactile perception, or (ii) thermotactile perception). }\end{array}$ \\
\hline \multicolumn{2}{|l|}{ Notes: } \\
\hline \multicolumn{2}{|r|}{$\begin{array}{l}\text { 1. 'Unusual' is defined in Table } 4 \text { : numbness and tingling at times other than during or after } \\
\text { vibration, gripping, cold, or finger blanching or at night that has occurred during the past } 4 \\
\text { weeks, normally occurs on } 4 \text { or more days a week and for } 4 \text { or more hours a day and causes a } \\
\text { problem for the affected person. }\end{array}$} \\
\hline \multicolumn{2}{|r|}{$\begin{array}{l}\text { 2. 'Probable disorder' means that the objective test result, when one test is performed, would be } \\
\text { obtained by chance on } 2.5 \% \text { or fewer occasions in an equivalent population not exposed to } \\
\text { hand-transmitted vibration. }\end{array}$} \\
\hline \multicolumn{2}{|r|}{$\begin{array}{l}\text { 3. 'Symptomatic digits' are fingers that are reported to suffer 'unusual' numbness or 'unusual' } \\
\text { tingling. }\end{array}$} \\
\hline \multicolumn{2}{|r|}{$\begin{array}{l}\text { 4. The sign of 'probable disorder' is any one (or more) positive test of either vibrotactile perception } \\
\text { (at either } 31.5 \text { or } 125 \mathrm{~Hz} \text { ) or thermotactile perception (hot or cold) at each site. For example, at } \\
\text { stage } 2 \text { pN, this must include a positive result from a test at each of the symptomatic fingers, not } \\
\text { two positive results on one symptomatic finger and a negative result on the other symptomatic } \\
\text { finger. }\end{array}$} \\
\hline \\
\hline \multicolumn{2}{|l|}{ 6. 0} \\
\hline \multicolumn{2}{|c|}{ 7. Reports of pain can be recorded using the evaluation method in Table 4 . } \\
\hline \multicolumn{2}{|r|}{$\begin{array}{l}\text { 8. Staging will normally be the responsibility of a qualified occupational physician who has } \\
\text { considered and excluded the possibility of other causes of the symptoms and signs and who } \\
\text { judges whether the evidence of the symptoms is sufficient for them to be accepted. }\end{array}$} \\
\hline \multicolumn{2}{|r|}{$\begin{array}{l}\text { 9. A diagnosis of peripheral neurological disorder due to hand-transmitted vibration requires that } \\
\text { exposure to hand-transmitted vibration is considered sufficient to cause the condition. }\end{array}$} \\
\hline
\end{tabular}


Table 9 Stockholm Workshop scale for the classification of vibration-induced white finger. [If a person has stage 2 in two fingers of the left hand and stage 1 in a finger on the right hand the condition may be reported as $2 L(2) / 1 R(1)$. There is no defined means of reporting the condition of digits when this varies between digits on the same hand. The scoring system is more helpful when the extent of blanching is to be recorded]

\begin{tabular}{|c|l|l|}
\hline Stage & \multicolumn{1}{|c|}{ Grade } & \multicolumn{1}{c|}{ Description } \\
\hline 0 & - & No attacks \\
\hline 1 & Mild & $\begin{array}{l}\text { Occasional attacks affecting only the tips of one or more } \\
\text { fingers }\end{array}$ \\
\hline 2 & Moderate & $\begin{array}{l}\text { Occasional attacks affecting distal and middle (rarely also } \\
\text { proximal) phalanges of one or more fingers }\end{array}$ \\
\hline 3 & Severe & Frequent attacks affecting all phalanges of most fingers \\
\hline 4 & Very severe & As in stage 3, with trophic skin changes in the finger tips \\
\hline
\end{tabular}


Table 10 Example of the combined use of symptoms and signs to define 'vascular stages' of the effects of hand-transmitted vibration. The vascular stages for the left and right hands may be reported separately (e.g. $\left.2_{\mathrm{V}-\mathrm{L}} 1_{\mathrm{V}-\mathrm{R}}\right)$.

\begin{tabular}{|c|c|}
\hline Stage & Symptoms and signs \\
\hline $0_{v}$ & No current vascular symptoms \\
\hline $0_{c}$ & $\begin{array}{l}\text { 'Unusual' coldness in the fingers } \\
\text { and } \\
\text { acceptable evidence of heightened sensitivity to cold (e.g., a sign of probable } \\
\text { disorder in a symptomatic finger in a cold provocation test performed to current } \\
\text { standards). }\end{array}$ \\
\hline $1 \mathrm{v}$ & $\begin{array}{l}\text { A report of finger blanching with clearly demarcated boundaries during the past } \\
24 \text { months (i.e. finger blanching score }>0 \text { ) on } 1 \text { finger of either hand } \\
\text { and } \\
\text { acceptable evidence of cold-induced vasospasm in the symptomatic finger } \\
\text { (e.g., evidence from independent witness, or photograph of fingers and face, or } \\
\text { a sign of probable disorder in the symptomatic finger in a cold provocation test } \\
\text { performed to current standards). }\end{array}$ \\
\hline $2 v$ & $\begin{array}{l}\text { A report of finger blanching with clearly demarcated boundaries during the past } \\
24 \text { months (i.e. finger blanching score }>0 \text { ) on } 2 \text { fingers of either hand } \\
\text { and } \\
\text { acceptable evidence of cold-induced vasospasm in the symptomatic fingers } \\
\text { (e.g., evidence from independent witness, or photograph of fingers and face, or } \\
\text { a sign of probable disorder in the symptomatic finger in a cold provocation test } \\
\text { performed to current standards). }\end{array}$ \\
\hline $3 v$ & $\begin{array}{l}\text { A report of finger blanching with clearly demarcated boundaries during the past } \\
24 \text { months (i.e. finger blanching score }>0 \text { ) on } 3 \text { fingers of either hand } \\
\text { and } \\
\text { acceptable evidence of cold-induced vasospasm in the symptomatic fingers } \\
\text { (e.g., evidence from independent witness, or photograph of fingers and face, or } \\
\text { a sign of probable disorder in the symptomatic finger in a cold provocation test } \\
\text { performed to current standards). }\end{array}$ \\
\hline $4 v$ & $\begin{array}{l}\text { A report of finger blanching with clearly demarcated boundaries during the past } \\
24 \text { months (i.e. finger blanching score }>0 \text { ) on } 4 \text { fingers of either hand } \\
\text { and } \\
\text { acceptable evidence of cold-induced vasospasm in the symptomatic fingers } \\
\text { (e.g., evidence from independent witness, or photograph of fingers and face, or } \\
\text { a sign of probable disorder in the symptomatic finger in a cold provocation test } \\
\text { performed to current standards). }\end{array}$ \\
\hline \multicolumn{2}{|c|}{$\begin{array}{l}\text { Notes: } \\
\text { 1. It might be considered appropriate for there to have been at least two attacks with } \\
\text { clearly demarcated blanching of the fingers within the past } 24 \text { months. } \\
\text { 2. Staging will normally be the responsibility of a qualified occupational physician who } \\
\text { has considered and excluded the possibility of other causes of the symptoms and } \\
\text { signs and who judges the vibration exposure and the evidence of the symptoms } \\
\text { sufficient for them to be accepted. }\end{array}$} \\
\hline
\end{tabular}




\section{Figure captions}

Figure 1 Method of scoring the areas of the digits affected by blanching, numbness, or tingling (after Griffin, 1982, 1990)

Figure 2 Elements of the cause-effect relationship for occupational health disorders. 

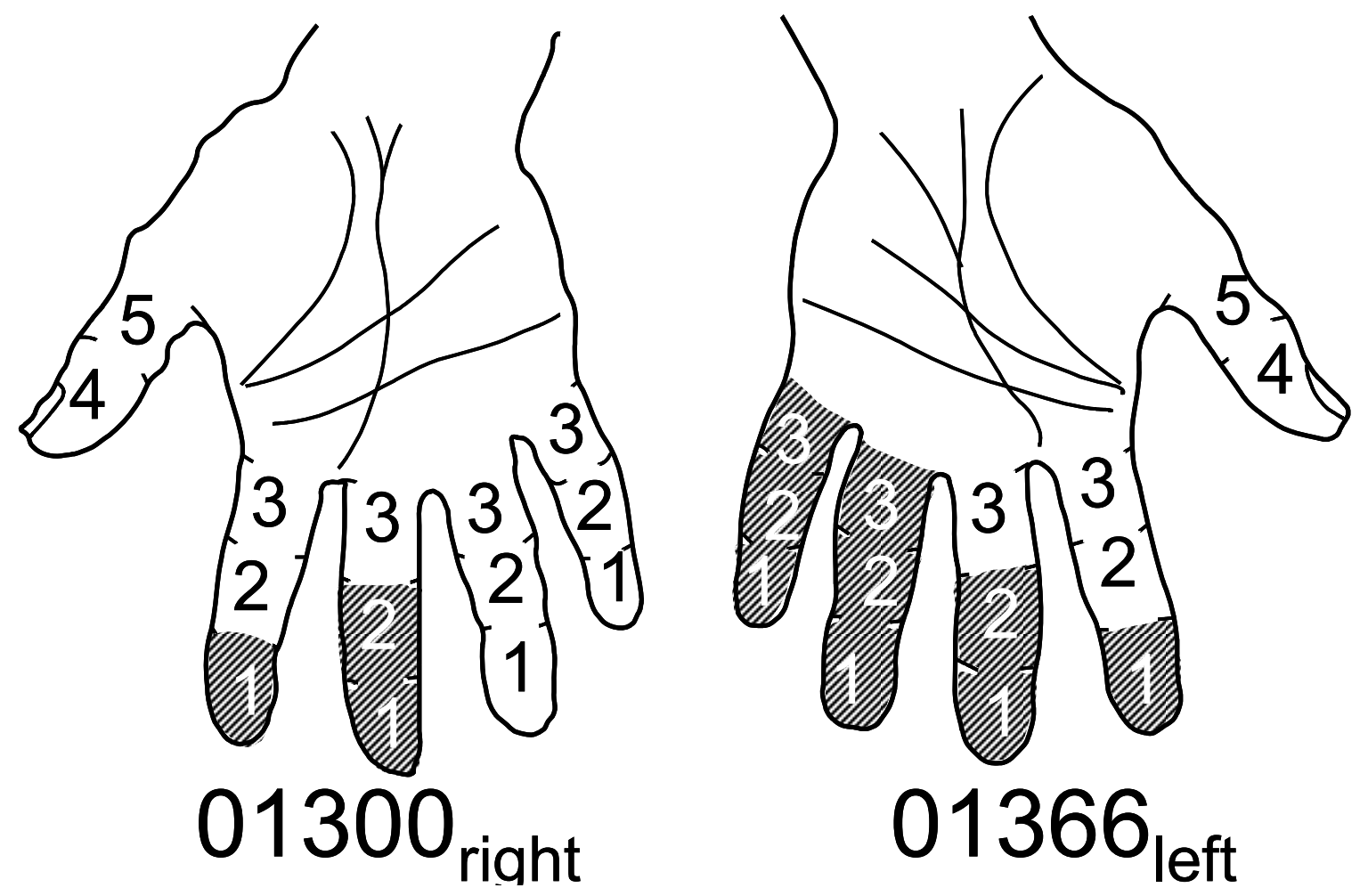

Figure 1 Method of scoring the areas of the digits affected by blanching, numbness, or tingling (after Griffin, 1982, 1990). Scores commence with the thumb. 


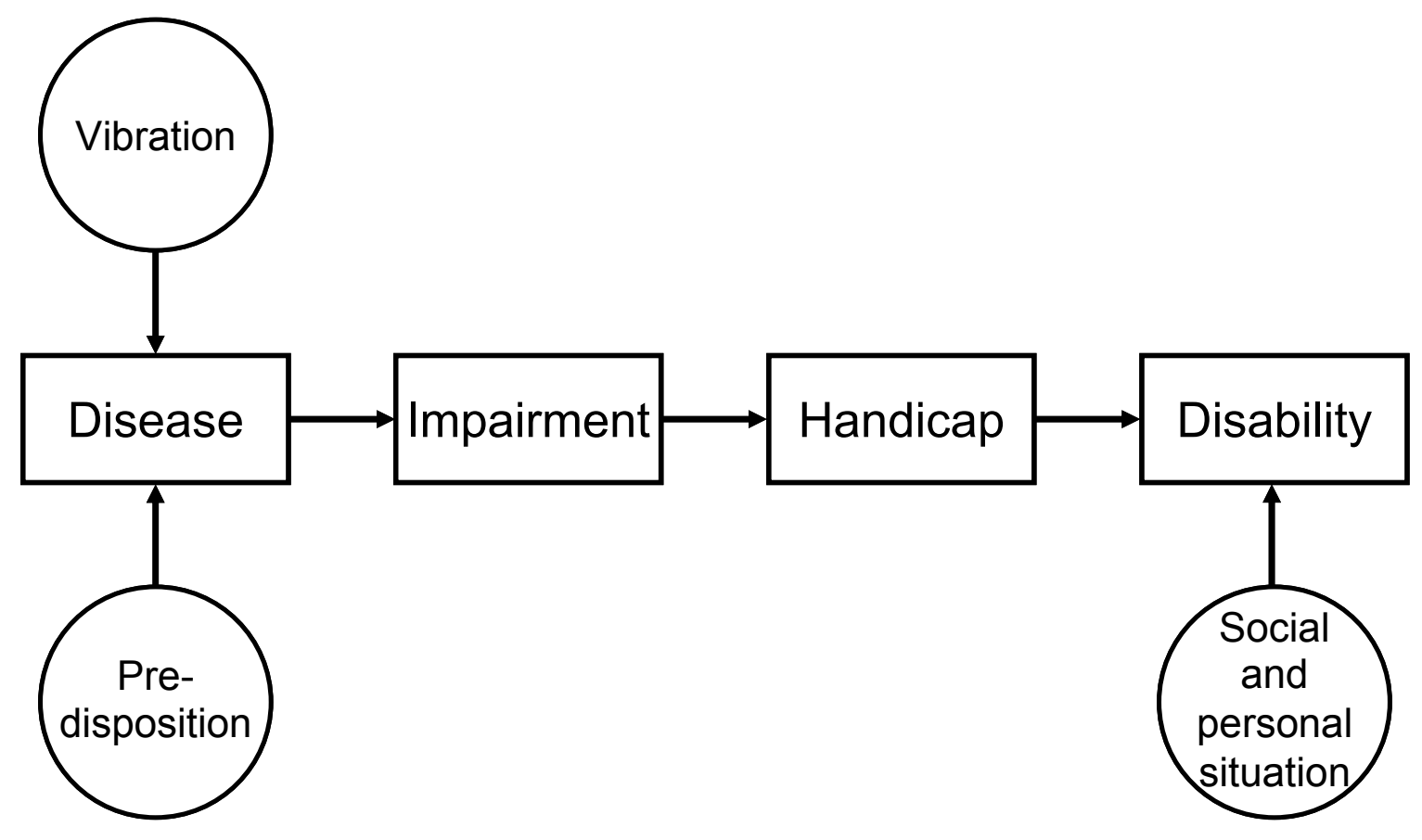

Figure 2 Elements of the cause-effect relationship for occupational health disorders. 